\title{
A questão do conhecimento e da verdade em Michel Foucault: uma leitura a partir do perspectivismo*
}

\author{
[The knowledge and truth issue according to Michel \\ Foucault: a reading matter departing from the \\ perspectivism]
}

\author{
Stéfano Gonçalves Regis Toscano* \\ Danilo José Viana da Silva
}

\begin{abstract}
Resumo
Este artigo consiste em uma investigação acerca do problema da verdade e do conhecimento segundo as análises de Michel Foucault. Tomando, como ponto de referência inicial, algumas questões, postas na série de palestras intituladas "A Verdade e as Formas Jurídicas" procurou-se, por meio de pesquisa bibliográfica, analisar como Foucault concebe a problematização do conhecimento, a relação sujeito-objeto, os enlaces entre procedimentos de conhecimento e procedimentos de dominação e a influência de Nietzsche para a compreensão dessas questões. Nesse plano, tentou-se defender que as hipóteses de Foucault coadunam-se com o que se convencionou denominar em termos nietzscheanos de perspectivismo ou, em outros termos, de que o conhecimento é a resultante do embate de perspectivas. Finalmente, vale ressaltar que, em face da necessidade de delimitação, buscou-se apresentar tal interpretação enfatizando a dimensão negativa do perspectivismo, logo, como crítica do conhecimento e da verdade.
\end{abstract}

Palavras-chave: Verdade; Poder; Perspectivismo; Michel Foucault.

\begin{abstract}
This article consists in an investigation about the problem regarding to the truth and the knowledge, according to Michel Foucault's analyzes. Considering point of reference some matters included in the series of meetings, intitled "the truth and the juridical forms" one has tried, through bibliographical, analysing to analyse. The way Foucault conceives the problematization concerning the acknowledgement, the relation subject versus object, the links between the knowledgement proceedings and domination procedures and Nietzshe's influence these matters.
\end{abstract}

Key-words: Truth; Power; Perspectivism; Michel Foucault.

\footnotetext{
* Este texto é uma versão, com algumas alterações, de um artigo apresentado na Revista Argumentum da Faculdade Marista do Recife, nº 04 (2011-2014).

* Doutor em Direito pela Universidade Federal de Pernambuco. Professor da Faculdade Marista do Recife, da Universidade Católica de Pernambuco e da Faculdade Boa Viagem.

- Doutorando em Direito pela Universidade Federal de Pernambuco. 


\section{Considerações iniciais}

Este artigo é essencialmente uma análise do problema do conhecimento e da verdade a partir da obra "A Verdade e as Formas Jurídicas" de Michel Foucault, um livro resultante de uma série cinco palestras ministradas no Brasil em 1973 na Pontifícia Universidade Católica do Rio de Janeiro.

A leitura do livro é importante para os estudiosos da filosofia, das ciências sociais de um modo geral e, inclusive, para os estudantes e teóricos do direito, ao menos pelos seguintes motivos: o trabalho de Foucault consiste em um ataque ao marxismo acadêmico daquele período, marcado por um forte economicismo, característico, inclusive, de alguns aportes ainda hoje persistentes. Ao invés de procurar saber como a consciência torna-se um reflexo ou resultado das condições econômicas, supondo um sujeito previamente definido, Foucault deseja investigar como as práticas sociais produzem novos domínios de saber e, além disso, novos objetos e novos sujeitos de conhecimento. Em outros termos, o que ocorre é um deslocamento, pois não se trata de analisar como um determinado conteúdo simbólico e material imprime-se na mente ou na consciência de homens representados como indivíduos racionais e potencialmente produtivos, mas como os próprios sujeitos são forjados (tal como o surgimento do próprio homo economicus) pelos saberes e pelas práticas sociais num sentido mais abrangente do que as meras práticas econômicas.

A obra permite também ao leitor aproximar-se das bases que sustentam a proposta de uma análise do discurso apartada da tentativa de identificar as regras, as regularidades estruturais dos fatos linguísticos, valorizando por outro lado, os fatos discursivos no que diz respeito aos seus aspectos estratégicos, de luta ou disputa.

Outro aspecto, ligado estreitamente ao primeiro mencionado consiste em tentar desenvolver sob um novo olhar a teoria do sujeito. Nesse caso, questionar a posição privilegiada de um sujeito dado e, portanto, não problematizado impõe que o gesto de pensálo considere-o sob o rastro de uma historicidade a ser desvelada:

Atualmente, quando se faz história - história das ideias, do conhecimento ou simplesmente história - 
atemo-nos a esse sujeito de conhecimento, a este sujeito da representação, como ponto de origem a partir do qual o conhecimento é possível e a verdade aparece. Seria interessante tentar ver como se dá, através da história, a constituição de um sujeito que não é dado definitivamente, que não é aquilo a partir do que a verdade se dá na história, mas de um sujeito que se constitui no interior mesmo da história, e que é a cada instante fundado e refundado pela história. É na direção desta crítica radical do sujeito humano pela história que devemos nos dirigir. (FOUCAULT, 2001, p.10)

Como surge então esse sujeito que representa a si mesmo e ao mundo, o sujeito da representação? Esse sujeito pretensamente universal e atemporal, porém advindo de uma temporalidade identificável e habitante provinciano de um espaço bem delimitado? Inúmeros são os caminhos de acesso às respostas possíveis, visto que inúmeras são as práticas e os lugares de onde elas provém. A constituição histórica do sujeito, sua emergência encontram, segundo Foucault, nas práticas judiciárias uma consistente fonte de investigação.

É no campo das práticas judiciárias, em meio a elas, por meio delas que sujeitos foram constituídos (sujeitos de direito, individuais, coletivos, etc.) e é igualmente nelas que a verdade, ou antes, uma determinada verdade ou verdades serão compostas assim como os objetos aos quais tais verdades remetem. A idéia de práticas, notadamente as judiciárias ou jurídicas pode ser facilmente apreendida por meio do trecho abaixo:

[...] a maneira pela qual, entre os homens, se arbitram os danos e as responsabilidades, o modo pelo qual, entre os homens, se arbitram os danos $\mathrm{e}$ as responsabilidades, o modo pelo qual, na história do Ocidente, se concebeu e definiu a maneira como os homens podiam ser julgados em função dos erros que haviam cometido, a maneira como se impôs a determinados indivíduos a reparação de algumas de suas ações e a punição de outras, todas essas regras ou, se quiserem, todas essas práticas regulares, é claro, mas também modificadas sem cessar através da história - me parecem uma das formas pelas quais 
nossa sociedade definiu tipos de subjetividade, formas de saber e, por conseguinte, relações entre o homem e a verdade que merecem ser estudadas. (FOUCAULT, 2001,p.11)

Todos esses problemas e objetivos, aliás, apontados na obra mesma não podem ser perdidos de vista pelo leitor de "A Verdade e as Formas Jurídicas" considerando que, sem eles, não é possível compreender amplamente o que Foucault quis atingir com o seu breve escrito.

Todavia, seria impossível e também indesejável que este texto, que pretende ser uma breve análise, procurasse abarcar toda essa gama de problemas que foi até aqui exposta. Apesar das razões que tornam as palestras de Foucault (notadamente a primeira) merecedoras de atenção (crítica de algumas abordagens marxistas, contribuições para o estudo da linguagem e crítica da concepção de conhecimento a partir, por exemplo de uma crítica da ideia de subjetividade), procurou-se concentrar em um ponto apenas, e, nesse caso, deixando-se levar pelo próprio título atribuído ao conjunto de conferências que constituem a obra, decidiu-se abordar a questão da verdade. Trata-se de um problema que atravessa todos os textos e, mais ainda, o tema maior para o qual os demais convergem constituindo-se como uma luz de fundo que os ilumina e que, ao mesmo tempo, projeta sombras que requerem, consequentemente, uma dedicada atenção.

Por último, cabe advertir que o comentário a seguir não se atém a uma leitura restrita de "A Verdade e as Formas Jurídicas," não pretende, portanto, ser uma espécie de guia de leitura voltado para uma análise detalhada parágrafo por parágrafo ou página a página do texto. Busquei apenas estabelecer algumas chaves interpretativas que permitam ao leitor desenvolver sua própria compreensão sem a pretensão de fornecer-lhe uma leitura canônica ou mais autorizada por acreditar que tal proposta destoaria completamente do que Foucault desejava que viesse a ocorrer com os seus trabalhos.

\section{O problema da verdade: por uma visão conflitiva}

O problema da verdade é o ponto basilar no qual inserem-se 
as questões pertinentes ao conhecimento, ao saber e às ciências. Em "A Verdade e as Formas Jurídicas" é possível reconhecer claramente a natureza dos posicionamentos de Foucault (2001, p. 08) acerca destes problemas:

Meu objetivo será mostrar-lhes como as práticas sociais podem chegar a engendrar domínios de saber que não somente fazem aparecer novos objetos, novos conceitos, novas técnicas, mas também fazem nascer formas totalmente novas de sujeitos e de sujeitos de conhecimento. O próprio sujeito de conhecimento tem uma história, a relação do sujeito com o objeto, ou, mais claramente, a própria verdade tem uma história.

Tradicionalmente concebe-se o conhecimento como uma relação entre o sujeito e o objeto, sendo função do sujeito apreender o objeto, e a do objeto, ser apreendido pelo sujeito. Nas práticas sociais é possível reconhecer novos procedimentos destinados a apreender os objetos, tal é a finalidade das técnicas e dos métodos. Assim, é plausível afirmar que a eclosão ou o surgimento de novas formas de investigação pode engendrar novos aspectos, dimensões ou facetas do objeto até então ocultas.

A visão de Foucault diferencia-se das concepções mais tradicionais como esta pela imposição de um ponto de vista duplamente problemático: as práticas sociais teriam a possibilidade de operar modificações, não apenas nos objetos, redimensionandoos - ou como em outros casos, apresentando objetos inéditos anteriormente não analisados ou até mesmo pensados -, mas poderiam também criar novos sujeitos ou sujeitos de conhecimento. Além de tudo, a posição de Foucault não encontra qualquer impulso motivador em aventurar conjeturas sobre, por exemplo, as condições ideais que precisariam convergir para que, em uma relação entre um sujeito e um objeto, o conhecimento pudesse efetivamente advir. Também não é pretensão dele identificar as condições objetivas e concretas que tornam acessível aos homens o conhecimento de coisas que antes não lhe eram conhecidas, que apenas "aguardavam" o momento propício para se deixarem revelar.

A questão é determinar o que deve ser o sujeito, a que questões ele está submetido, qual o seu status, que posição deve ocupar no real ou no imaginário para se tornar sujeito legítimo 
deste ou daquele tipo de conhecimento; em suma, trata-se de determinar seu modo de "subjetivação": pois este não é evidentemente o mesmo quando o conhecimento em pauta tem a forma de exegese de um texto sagrado, de uma observação de história natural ou de análise de comportamento de um doente mental. Mas a questão é também e ao mesmo tempo determinar em que condições alguma coisa pôde se tornar objeto para um conhecimento possível, como ela pôde ser problematizada como objeto a ser conhecido, a que procedimento de recorte ela pôde ser submetida, que parte dela própria foi considerada pertinente. Tratase, portanto, de determinar seu modo de objetivação, que tampouco é o mesmo de acordo com o tipo de saber em pauta. (FOUCAULT, 2004, p. 235).

Trata-se de questionar o conhecimento tentando pôr em relevo a natureza fabricada, produzida, não apenas do objeto, mas também do próprio sujeito de conhecimento. Sob quais circunstâncias, atendendo a quais exigências o sujeito de conhecimento - deve-se dizer, de um determinado tipo de conhecimento (área, ciência ou disciplina) - conseguiu ser reconhecido como legítimo.

Nietzsche afirmava que o conhecimento corresponde a uma invenção. Nesse sentido, o conhecimento não possui origem, ele não é algo que já se encontrava aqui ou acolá, dependendo apenas que o homem dele tivesse ciência. $\mathrm{O}$ conhecimento, segundo a compreensão que Foucault faz da concepção de Nietzsche, não está na natureza, no mundo ou na natureza humana. A relação entre o conhecimento e as coisas a conhecer é arbitrária e apoiada em procedimentos de dominação.

Não há, portanto, no conhecimento uma adequação ao objeto, uma relação de assimilação, mas, ao contrário, uma relação de distância e dominação; não há no conhecimento algo como felicidade e amor, mas ódio e hostilidade; não há unificação, mas sistema precário de poder. (FOUCAULT, 2001, p. 22).

$\mathrm{O}$ processo de conhecimento entendido sob esses parâmetros não viabiliza certamente a formação de um saber homogêneo, a ser compartilhado por todos que se disponham a domar a natureza e os seres a ela pertencentes, isto porque o conhecimento implica em conflitos e relações de luta dos homens, uns contra os outros, derivando daí o motivo de ter sido afirmado, 
em um outro momento, o vínculo espúrio entre o conhecimento, o ódio e a hostilidade.

Compreende-se, então, porque Nietzsche afirma que o filósofo é aquele que mais facilmente se engana sobre a natureza do conhecimento por pensá-lo sempre na forma da adequação, do amor, da unidade, da pacificação. Ora, se quisermos saber o que é o conhecimento, não é preciso nos aproximarmos da forma de vida, de existência, de ascetismo, própria ao filósofo. Se quisermos realmente conhecer o conhecimento, saber o que ele é, apreendê-lo em sua raiz, em sua fabricação, devemos nos aproximar, não dos filósofos mas dos políticos, devemos compreender quais são as relações de luta e de poder. E é somente nessas relações de luta e de poder- na maneira como as coisas entre si, os homens entre si se odeiam, lutam, procuram dominar uns aos outros,querem exercer, uns sobre os outros, relações de poder- que compreendemos em que consiste o conhecimento. (FOUCAULT, 2001, p. 23).

A consagrada figura do filósofo, geralmente esboçada em termos quietistas e apaziguadores, corresponde muito mais às imagens vulgarmente atribuídas ao seu ofício e às suas qualidades do que àquilo que, no meio social, realmente acontece com este singular protagonista: encarnar o combatente feroz que carrega o estandarte de sua própria perspectiva ou concepção de verdade.

A história da filosofia foi constantemente tratada ao longo dos séculos como um lento e gradual avanço em direção a formas e sistemas de pensamento mais apurados e evoluídos. O devir histórico, apresentado como uma via de mão única, ocultou o caráter repressivo das narrativas canônicas, obscureceu o comprometimento da historiografia filosófica com a constituição de um saber estratégico, voltado para a difusão de um conhecimento formatado, cerceador de questionamentos não condizentes com as agendas de discussões acadêmicas estabelecidas pelos mandarinatos intelectuais.

Tudo isto é válido, de um ponto de vista disciplinar, sobretudo para a história da filosofia e até mesmo para estudos afins, como acontece nos quadrantes da Filosofia do Direito e sua história. Da antiguidade aos tempos modernos os exemplos dos cortes, esquecimentos e simplificações abundam. Existem aqueles que veem na manutenção das visões caducas a permanência consciente ou inconsciente do platonismo, do idealismo. 
Certamente, Platão não é Descartes, que não é Kant, mas esses três, partilhando vinte séculos de mercado idealista, açambarcam a filosofia, ocupam todo o lugar, e não deixam nada para o adversário, nem mesmo migalhas. $\mathrm{O}$ idealismo, a filosofia dos vencedores desde o triunfo oficial do cristianismo que se tornou o pensamento de Estado - Deus, como Nietzsche, tem razão em considerar o cristianismo um platonismo para uso da população! ,passa tradicionalmente por ser a única filosofia digna desse nome.

Hegel, o batedor desse mundo, dedica uma louca energia a afirmar em suas Lições sobre a história da filosofia dadas na Universidade - o lugar ad hoc - que só existe uma filosofia (a dele, evidentemente!), que todas as do passado a preparam pois evoluem organicamente segundo um plano - uma espécie de filodicéia! -, que essa construção afirma a onipotência da razão na história, certamente, mas a razão se sobrepõe também a outras palavras: o Conceito, a Idéia, ou...Deus! (ONFRAY,2008, p. 16)

Não há como disfarçar que à filosofia também pode se aplicar o antigo ditado, nem por isso menos verdadeiro, de que a história tende a ser delineada pelas narrativas dos vencedores. Cumpre então fazer um esforço para ultrapassar o véu de fumaça obscurecedor da dimensão das crateras deixadas na zona do atrito em que se deu o choque das forças. Assim, torna-se possível fazer aparecer, no lugar da verdade imposta pelo discurso dominante, a história do pensamento dos que sucumbiram, muito menos pela fragilidade de suas ideias, do que pela força concreta, muitas vezes brutal, dos aparelhos e instituições que acompanhavam os discursos e toda a filosofia que serviu para legitimar e sustentar a lógica e os objetivos a serviço da dominação.

\section{Verdade e perspectivismo nietzscheano}

Foucault em "A Verdade e as Formas Jurídicas" propõe, entre outros objetivos, uma leitura de Nietzsche empenhada em buscar elementos compatíveis com a estruturação de um modelo de análise da política da verdade. Para tanto, a interpretação de Foucault (2001, p. 25) pretende enfatizar a abordagem perspectivista do pensador alemão.

Nietzsche afirma que não há ser em si, como também não pode haver conhecimento em si [...] quer dizer que 
não há uma natureza do conhecimento, uma essência do conhecimento, condições universais para o conhecimento, mas que o conhecimento é, cada vez, o resultado histórico e pontual de condições que não são da ordem do conhecimento [...]. Assim podemos compreender [...] que o conhecimento é sempre uma perspectiva [...]. O caráter perspectivo do conhecimento não deriva da natureza humana, mas sempre do caráter polêmico e estratégico do conhecimento. Pode-se falar do caráter perspectivo do conhecimento porque há batalha e porque o conhecimento é o efeito dessa batalha.

O conhecimento revela-se como a resultante de relações de forças, de oposições de diferentes perspectivas em conflito.

À primeira vista, o perspectivismo estaria a apontar para uma concepção de conhecimento variável de sujeito a sujeito ou, em outros termos, de acordo com o ponto de vista do observador. De tal modo, um número infinito de verdades seria obtido, caso fosse considerado um número infindável de sujeitos. A compreensão do perspectivismo em tais balizas não passaria de ingenuidade, pois um hipotético tratado sobre o conhecimento nada mais seria que o empreendimento antecipadamente malogrado em sua proposta de proceder ao levantamento das verdades individuais. Portanto, na raiz do perspectivismo nietzschiano, à luz da interpretação desenvolvida por Foucault, o conhecimento corresponderia ao produto da disputa de perspectivas em torno de seres, coisas, enfim, dos objetos de conhecimento.

No âmbito das práticas sociais seria possível identificar momentos em que os saberes, as perspectivas sobrepõem-se uns aos outros, dominando-se por relações de submissão, cooptação ou repulsão, de um lado, e do outro, estabelecendo alianças e conluios contra os saberes que precisam ser negados, sujeitados.

Talvez não seja excesso de zelo afirmar que o conhecimento jamais é produzido em um vácuo, num espaço etéreo. Toda sua produção está inexoravelmente ligada ao contexto no qual ele é produzido, por isso, ele é ao mesmo tempo fator condicionante, responsável pela afirmação ou subversão do contexto, e, por outro lado, um elemento condicionado. O jogo de forças ou de poder intrometido na produção, circulação e renovação do conhecimento 
pode ser visto em desenvolvimentos mais ou menos vigorosos. Por conseguinte, se houvesse por parte de alguém o interesse de fixar uma escala de intensidades das forças implicadas, do grau de submissão de uma força a outra, é bem provável que a produção de conhecimento mais comprometida com a dominação e a violência, em suas diversas formas de expressão, seria, para dar um exemplo, a dos contextos coloniais e neocoloniais.

No colonialismo, o confronto perspectivístico da verdade tende a ser representado essencialmente por duas posições opostas: a do colonizado e a do colonizador. Trata-se de uma tendência, pois é certo que outras perspectivas continuem a subsistir, mas, de um modo geral, elas serão marcos de uma gradação que se prolonga de um extremo a outro. Em um outro sentido, pode-se assistir à afirmação de posturas arredias a tomarem partido.

A violência permeia tanto o contexto da colonização quanto o da descolonização. Isto assim acontece por se tratar de uma conjuntura em que grupos rivais se sucedem no espaço demarcado pelos conflitos. Não há meio termo. Quando um grupo toma a cena, por exemplo, o dos colonizadores, isto se deve ao fato do grupo dos colonizados ter perdido o terreno que antes lhe pertencia. Também não há meio termo por não ser aceitável se falar em conciliação, ou seja, o anseio do colonizado consciente é a queda do colonizador enquanto que o desejo do colonizador é a derrocada de tudo o que pode a ele resistir.

A descolonização é o encontro de duas formas congenitalmente antagonistas, que têm precisamente a sua origem nessa espécie de substantificação que a situação colonial excreta e alimenta. O primeiro confronto dessas forças se desenrolou sob o signo da violência, e sua coabitação - mais precisamente a exploração do colonizado pelo colono - prosseguiu graças às baionetas e aos canhões. $\mathrm{O}$ colono e o colonizado são velhos conhecidos. E, na verdade, o colono tem razão quando diz que "os" conhece. Foi o colono que fez e continua a fazer o colonizado. $\mathrm{O}$ colono tira a sua verdade, isto é, os seus bens, do sistema colonial. (FANON, 2005, p. 52).

Portanto, ao que tudo indica, fundamentalmente é do poder das armas que se trata, mas armas certamente não são apenas 
canhões e baionetas. Ao lado do colono existe todo um séquito de cooptados, menos pela promessa de armas que possam lhes ser oferecidas, do que pela prevalência das idéias do colonizador das quais serão eles os porta-vozes, repetidores incansáveis, sinceros ou não. $\mathrm{Na}$ relação entre colono e colonizado faz-se substancial a introjeção por parte deste dos sistemas, dos esquemas de avaliação, enfim, das verdades apregoadas pelo dominador, a tal ponto em que seja o próprio dominado aquele que mais se aplicará por procurar, e provavelmente por encontrar, os motivos da sua inferioridade, do seu fracasso e impotência diante do colonizador. Nesse ponto, o saber do colonizador atinge sua capacidade máxima de sujeitar o colonizado.

O nível de violência contido numa relação dessa natureza aparentemente nada tem a ver com o feitio das relações intersubjetivas das sociedades ocidentais democráticas, assentadas em princípios como os da liberdade e do pluralismo. Porém, a mera afirmação de um conjunto de balizas teóricas pouco valem, geralmente, nos contextos concretos em que são afirmadas.

$\mathrm{O}$ que até o momento procurei pôr em relevo foram as relações entre a verdade e o perspectivismo, e assim o fiz porque a visão do conhecimento em termos conflitivos é a mola propulsora de A Verdade e as Formas Jurídicas.

\section{Os saberes sujeitados}

Há, entretanto, um outro caminho para avaliar os múltiplos itinerários percorridos por Foucault em suas pesquisas acerca da verdade ou, para ser mais condizente com a sua forma de pensar, entre os conflitos de verdades e dos efeitos advindos desses confrontos: a análise da relação entre os saberes (termo utilizado muitas vezes em caráter substitutivo ao de verdade) totalizantes ou dominantes e os saberes sujeitados tal como é desenvolvida em suas aulas do curso "Em defesa da Sociedade", além da concepção de genealogia. A análise dessas concepções dentre outras, desenvolvidas nessa obra (também resultantes de aulas ministradas pelo filósofo), podem ser muito úteis para a compreensão de algumas das discussões levadas a cabo em "A Verdade e as Formas Jurídicas".

Para compreender mais precisamente a relação conflituosa 


\section{ÁGORA FiLOSÓFICA}

entre os saberes é preciso atentar para os primeiros desenvolvimentos dados por Foucault às suas aulas. Portanto, podese observar que a aula inicial dos cursos de 1976 é marcada por uma tentativa de prestação de contas aos seus ouvintes. Tratava-se de apresentar algo como o esboço da trajetória por ele estabelecida em suas pesquisas. Não obstante, aquilo que Foucault, em um primeiro manipulação, oferece aos seus ouvintes, assemelha-se mais a um conjunto de trabalhos dispersos

[...] sobre a história do direito penal;alguns capítulos referentes à evolução, à institucionalização da psiquiatria no século XIX; considerações sobre a sofística ou sobre a moeda grega, ou sobre a inquisição na Idade Média ; o esboço de uma história da sexualidade e das práticas de confissão no século XVII ou dos controles da sexualidade infantil nos séculos XVIII-XIX; a localização da gênese de uma teoria e de um saber da anomalia, com todas as técnicas que lhe são vinculadas. tudo isso marca passo, não avança; tudo isso se repete e não está amarrado. No fundo, isso não pára de dizer a mesma coisa e, contudo, talvez, não diga nada; tudo isso se entrecruza numa embrulhada pouco decifrável, que não se organiza muito; em suma, como se diz, não dá resultado. (FOUCAULT, 1999, p.6)

A declaração, um tanto desconcertante de que as pesquisas se repetem, não avançam, pode ser interpretada como um indício da angústia sentida pelo filósofo. Sentimento, aliás, bastante comum em qualquer trabalho de pesquisa levado a cabo com seriedade. Do ponto de vista do senso comum acadêmico, a elaboração das investigações e das pesquisas científicas é encarada sob uma ótica linearizante, como se todo trabalho resultasse de um processo organizado em que as fases da pesquisa sucedem-se umas às outras harmoniosa e gradativamente. Sabe-se, todavia, o que acontece na maior parte das vezes: as pesquisas materializam-se após inumeráveis avanços e recuos, cujas entrelinhas, caso pudessem ser lidas, evidenciariam - para além da tonalidade de segurança que só se adquire possivelmente ao final da investigação - a incerteza que envolve o pesquisar.

Nesse sentido, Foucault não parece sentir maior 
constrangimento em revelar certo impasse em seus estudos. Por outro lado, insinua que eles não param de dizer a mesma coisa. $\mathrm{O}$ elo de ligação apresenta-se como um problema a ser desvendado. Onde encontrar tal ponto de tensão e de união entre a fragmentação e a continuidade? Provavelmente na eclosão observada na segunda metade do século XX de um conjunto de discursos, de críticas locais e pontilhadas, não submetidas a um regime teórico comum, como no caso do marxismo e da psicanálise. Na tessitura de tais discursos, da antipsiquiatria, contra a dominação sexual, contra o aparelho penal e judicial, Foucault (1999, p. 11-12) acredita ter se deparado com a insurreição de saberes que foram sujeitados.

[...] por "saber sujeitado", entendo duas coisas. De uma parte, quero designar, em suma, conteúdos históricos que foram sepultados, mascarados em coerências funcionais ou em sistematizações formais [...]. Portanto, os "saberes sujeitados" são blocos de saberes históricos que estavam presentes e disfarçados no interior dos conjuntos funcionais e sistemáticos, e que a crítica pôde fazer reaparecer [...].

Em segundo lugar [...]. Por "saberes sujeitados", eu entendo igualmente toda uma série de saberes que estavam desqualificados como saberes não conceituais, como saberes insuficientemente elaborados: saberes ingênuos, saberes hierarquicamente inferiores, saberes abaixo do nível do conhecimento ou da cientificidade requeridos [...]. E foi pelo reaparecimento desses saberes [...] : o do psiquiatrizado, o do doente, o do enfermeiro, o do médico [...] que denominarei, se quiserem, o "saber das pessoas". (e que não é de modo algum um saber comum, um bom senso, mas ao contrário, um saber particular, um saber local, regional, um saber diferencial, incapaz de unanimidade [...] que foi feita a crítica.

Foucault acredita localizar temporalmente a emergência dos saberes sujeitados, assim compreendidos como um amálgama de fragmentações discursivas, ou, mais simplesmente, discursos, cuja eficácia parece sustentar-se justamente no distanciamento frente a qualquer produção teórica generalizante ou de conjunto. Nada impede, entretanto, que a origem desses saberes encontre sua 
semente nas teorias globais, desde que se compreenda que sua potência crítica só pode manifestar-se plenamente na medida em que se desprendem de suas matrizes discursivas envolventes, totalitárias.

Pode-se então melhor entender em que consistem os saberes sujeitados. Tratam-se de saberes sepultados, esquecidos. Não é por puro diletantismo que Foucault evoca, tanto pela voz como pelo ofício de pesquisador, a persistente busca dos textos empoeirados de um tempo já grisalho. O esmaecimento de certos saberes efetivase paralelamente ao enaltecimento de outros, dotados de maior coerência funcional, sistematicidade ou de qualquer outro critério de legitimação, cuja finalidade maior, enfim, é a de acobertar os embates travados em torno da verdade.

Nos dias atuais inúmeras vozes insurgem-se contra a tendência totalizante de certos saberes vinculados a políticas de dominação e eliminação. Toda cultura é composta por diversos sistemas de saber locais, colocados constantemente sob ameaça de desaparecimento.

Em geral, os sistemas ocidentais de saber são considerados universais. No entanto, o sistema dominante também é um sistema local, com sua base social em determinada cultura, classe e gênero. Não é universal em sentido epistemológico. É apenas a versão globalizada de uma tradição local extremamente provinciana. Nascidos de uma cultura dominadora e colonizadora, os sistemas de saber modernos de saber são, eles próprios, colonizadores.

A ligação entre saber e poder é inerente ao sistema dominante [...]. O poder [...] é introduzido na perspectiva que vê o sistema dominante não como uma tradição local globalizada, mas como uma tradição universal, inerentemente superior aos sistemas locais. Contudo, o sistema dominante também é produto de uma cultura particular. (SHIVA, 2003, p. 21-22).

Embora seja cabível defender que o universalismo tenha encontrado o seu apoio mais promissor nas vigas dos sistemas ocidentais de pensamento, não parece ser sustentável afirmá-lo como uma característica exclusiva do ocidente e, ainda mais, como um qualificativo associável apenas a sociedades complexas, calcadas, por exemplo, na divisão social do trabalho e na 208 • Universidade Católica de Pernambuco 
especialização crescente das atividades econômicas e da lógica produtiva, como defende Vandana Shiva. Isto porque um rápido exame sobre as cosmogonias de povos muito antigos, como se dá na narrativa de Gilgamesh e em sociedades primitivas polinésias estudadas por Sahlins (2006), ou mesmo nas perspectivas radicalistas e salvíficas do oriente próximo, é capaz de revelar traços de universalismo. Em contrapartida, as análises de Vandana Shiva parecem-me valiosas na medida em que disponibilizam um arsenal de conceitos explicativos para a compreensão dos mecanismos de colonização e sua imbricação com os postulados teóricos universalizantes do ocidente.

Pode-se também compreender como saberes sujeitados aqueles forjados nas batalhas cotidianas, os saberes que emanam das pessoas, demasiadamente inferiores e ingênuas, incapazes de soerguerem-se ao patamar de cientificidade ou de conhecimento consagrado, também discrepantes do senso comum por operarem em níveis consideravelmente menores de generalidade e penetração. Configuram-se como saberes locais, regionais, desprovidos de esteio teórico, ou seja, à primeira vista, desconectados da primeira acepção dos saberes sujeitados anunciada por Foucault, ao atentar-se que estes não estão necessariamente desprovidos de conteúdos técnicos, eruditos de uma produção teórica. A partir do aparente paradoxo de unir sob inscrição de saberes sujeitados as duas classes de saberes referidas descortina-se a proposta do projeto ou proposta por ele denominada de genealogia.

\section{A genealogia}

Uma terceira via apropriada por Foucault para perscrutar o problema da verdade consistiu em uma releitura da concepção nietzschiana de genealogia. $\mathrm{O}$ que há por trás do projeto genealógico? Persistindo na imposição de uma pergunta já formulada, em que medida os trabalhos de Foucault apontam algumas constantes, a despeito de sua diversidade temática? Uma possível resposta seria: na tentativa de fazer ouvir os sussurros, o descontentamento dos excluídos da história, não pelas vias dos discursos oficiais, mas pela recuperação dos saberes adrede esquecidos. 
A junção dos conhecimentos eruditos de conteúdo histórico aos saberes locais das pessoas consiste de um modo mais geral na genealogia.

Chamemos, se quiserem, de "genealogia" o acoplamento dos conhecimentos eruditos e das memórias locais, acoplamento que permite a constituição de um saber histórico das lutas e a utilização desse saber nas práticas atuais. [...]. Tratase, na verdade, de fazer que intervenham saberes locais, descontínuos, desqualificados, não legitimados, contra a instância teórica unitária que pretenderia filtrá-los, hierarquizá-los, ordená-los em nome de um conhecimento verdadeiro, em nome dos direitos de uma ciência que seria possuída por alguns. (FOUCAULT, 1999, p. 13).

Advindos da passagem acima alguns elementos novos podem ser correlacionados à noção de genealogia. Em primeiro lugar, o desempenho de uma função aplicativa no campo da história, evidenciando a possibilidade de recuperação dos saberes sujeitados para utilizá-los como recursos estratégicos nos confrontos atuais, em outros termos, uma função de reconstituição. Em segundo lugar, depreende-se a compreensão da genealogia como recuperação de discursos de verdades no intuito de promover um embate entre os discursos ou saberes sujeitados contra toda tendência de totalitarismo científico, epistemológico ou ainda virtualmente arvorada na afirmação de um conhecimento genuíno, o que vem a apontar para uma função de enfrentamento. A segunda acepção arvora-se no pressuposto de que uma suposta hipossuficiência dos saberes sujeitados, frente aos saberes dominantes, podem apenas ser estabelecidas a posteriori, como resultantes de combates em que a fixação do que se compreende como conhecimento e verdade não pode basear-se em qualquer critério tomado como irrefutável ou superior, pelo contrário, são os atritos resultantes das interações, das batalhas que permitem ao vencedor estabelecer seus próprios critérios de acesso à verdade e seus efeitos decorrentes.

As genealogias são, muito exatamente, anticiências.

Não que elas reivindiquem o direito lírico à ignorância e ao não-saber, não que se tratasse da recusa de saber 
ou do pôr em jogo, do pôr em destaque os prestígios de uma experiência imediata, ainda não captada pelo saber. Não é disso que se trata. Trata-se da insurreição dos saberes. Não tanto contra os conteúdos, os métodos ou os conceitos de uma ciência, mas de uma insurreição sobretudo e acima de tudo contra os efeitos centralizadores de poder que são vinculados à instituição e ao funcionamento de um discurso científico organizado no interior de uma sociedade como a nossa [...]. É exatamente contra os efeitos de poder próprios de um discurso considerado científico que a genealogia deve travar o combate. (FOUCAULT, 1999, p. 14).

A genealogia distancia-se do deslumbramento de um saber supostamente puro, em estado bruto, livre de intromissões teóricas, sobretudo porque uma concepção de conhecimento assentada nesses termos estaria a soçobrar entre a ignorância e a inocência. A efetivação do olhar genealógico apoia-se na postura de uma perspectiva teórica cuja finalidade é a de permitir a recuperação dos saberes sujeitados ao atuar como instrumento de mediação entre o olhar do pesquisador e esses saberes.

Sendo assim, as genealogias operam como diretrizes anticientíficas, mas preponderantemente nos limites em que o conhecimento dito científico apresenta-se como contrafação, distorção, daquilo que pode ser entendido como conhecimento, promovido pela postulação absolutista de critérios de cientificidade, camufladores da arbitrariedade implicada na escolha de quaisquer critérios, caso se concorde com o caráter perspectivo da verdade. As genealogias atuam como mecanismos de resistência aos efeitos centralizadores de poder do saber científico.

\section{Considerações Finais}

É possível depreender do que foi dito que, segundo Foucault, "verdade" é uma palavra a ser usada no plural. Não existe "a verdade" mas verdades em disputa. Os confrontos entre as verdades não residem em uma ordem abstrata, dizem respeito, isto sim, a confrontos que expressam visões de mundo distintas, muitas vezes opostas e, em diversos casos, inconciliáveis. Os conflitos 
entre as verdades, além disso, encontram-se nos choques entre conhecimentos distintos, entre ciências diferenciadas, mas também nas disputas intestinas de uma ciência em particular.

Aparentemente a afirmação de tamanha diversidade de saberes, discursos, revelaria uma tendência relativista no pensamento de Foucault, porém, como procurei argumentar acima, isso não passa de um equívoco, pois a ideia de conhecimento do mestre françês aponta para uma concepção de conhecimento (e de verdade) mais alinhável à visão perspectivística de Nietzsche (tal como foi batizada a concepção de conhecimento nietzscheana por alguns estudiosos de sua obra). O perspectivismo, como a própria denominação permite entender, parte do pressuposto de que a verdade é uma questão de perspectiva, de ponto de vista, de ângulo, de tal forma, o conhecimento é, grosso modo, o resultado de choques que, por sua vez, podem derivar de alianças, encontros maus ou favoráveis de diversas perspectivas em contínuos entrechoques e alinhamentos. Nesse sentido, cabe mais uma vez advertir, cada perspectiva diz respeito a modos de vida, a sentimentos (medo, raiva, ressentimento), paixões, valores e estilos de vida, logo, a idéia de um conhecimento puro, livre das condições concretas de existência corresponde a um construto destituído de sustentabilidade.

Consequentemente, Foucault ao investigar as lutas entre os discursos de verdades não se mostrará inclinado a propor um método virtualmente capacitado a identificar o discurso mais autêntico, pretensamente mais verdadeiro, o que ele pretende efetivamente realizar é uma análise das condições históricas, sociais, políticas que tornaram possível a emergência de determinados saberes, de determinadas concepções de verdade em detrimento de outras deixando portanto mais clara a relevância da proposta genealógica e do confronto entre saberes sujeitados e saberes totalizantes.

\section{Referências}

CASTRO, Edgardo. Vocabulário de Foucault: um percurso pelos seus temas, conceitos e autores. Belo Horizonte: Autêntica Editora, 2009.

FANON, Frantz. Os condenados da terra. Juiz de Fora-MG: Ed. UFJF, 2005 
FOUCAULT, Michel. Em defesa da sociedade: curso no Collège de France (1975-1976). São Paulo: Martins Fontes, 1999.

Ética, sexualidade, política. Organização e seleção de textos Manoel Barros da Motta. Rio de Janeiro: Forense Universitária, 2004. (Ditos \& Escritos, V)

A verdade e as formas jurídicas. Rio de Janeiro: Nau Editora, 1999.

ONFRAY, Michel. Contra-história da filosofia: as sabedorias antigas, 1; tradução Monica Stahel. São Paulo, WMF Martins Fontes, 2008.

SHIVA, Vandana. Monoculturas da mente: perspectivas da biodiversidade e da biotecnologia. São Paulo: Gaia, 2003. 